\title{
EDUCAÇÃO AMBIENTAL E A GESTÃO DOS RECURSOS HÍDRICOS: SUBSÍDIOS PARA UMA REFLEXÃO INTEGRADA
}

\author{
Veiga, B. G. A.'; Malafaia, G. ${ }^{1,2^{*}} \&$ Castro, A. L. S. ${ }^{1,2}$ \\ 1 - Curso de Tecnologia em Gestão Ambiental, Instituto Federal Goiano - campus Urutaí \\ 2 - Curso de Ciências Biológicas, Instituto Federal Goiano - campus Urutaí \\ ${ }^{*}$ Corresponding author: guilhermebioufop@yahoo.com.br
}

\begin{abstract}
Veiga, B. G. A.; Malafaia, G. \& Castro, A. L. S. (2013) Environmental education and water resource management: subsidies for an integrated reflection. Braz. J. Aquat. Sci. Technol. 17(1): 1-11. eISSN 1983-9057. Environmental Education focusing on Integrated Water Resources Management has increasingly grown with the implementation of the Brazilian Water Resources Policy. However, environmental educators have not yet occupied their rightful place in the management and decision making on environmental issues. This is partly due to peculiarities on the field of water resources. These are mainly technical, which limits critical Environmental Education supporting the development of new prospects for sustainable water use. This article therefore seeks to recover the role of environmental education and environmental educators as critical mediators of the processes of water management.
\end{abstract}

Key words: Environmental Education, Integrated Water Resources Management.

\section{A GESTÃO INTEGRADA DE RECURSOS HÍDRICOS (GIRH)}

A declaração resultante da Conferência Internacional de Água e Meio Ambiente (realizada em Dublin, Irlanda, nos dias 26 a 31 de janeiro de 1992) estabelece que a Gestão Integrada de Recursos Hídricos (GIRH) pressupõe todos os usos da água como interdependentes, sob o enfoque da sustentabilidade. Para tanto, estabelece como princípios: (1) a proteção e uso sustentável da água doce como base da vida, do desenvolvimento e do meio ambiente; (2) a tomada de decisões de forma participativa entre os governos, os diferentes utilizadores e a sociedade em geral; (3) a valorização do papel da mulher como gestora e guardiã da água e (4) o reconhecimento da água como um bem econômico.

Embora tais princípios sejam orientadores da política global das águas, eles despertam significados específicos em cada um dos contextos nacionais onde são aplicados. No Brasil, a Política Nacional de Recursos Hídricos (Lei n 9.433/1997 - Brasil, 1997) estabelece a água como um bem de domínio público, recurso limitado, que possui valor econômico e seu uso deve ser planejado segundo a ótica dos múltiplos e possíveis aproveitamentos. Define ainda que a gestão deve ser descentralizada e contar com a participação social, considerando a bacia hidrográfica como a nova unidade de referência para o planejamento.

Alguns de seus princípios e instrumentos trouxeram importantes transformações para o cenário da gestão das águas no Brasil, embora não estejam implementados em todo o território nacional e nem com a mesma intensidade. Essas transformações não se deram de forma rápida e ampla em toda a sociedade, representando um processo de mudança nas formas de leitura e interpretação do ambiente e da produção e sistematização de conhecimentos e técnicas.

Nesse sentido, a Educação Ambiental (EA) tem desempenhado gradativamente um papel fundamental na mudança do referencial histórico com o qual os recursos hídricos vinham sendo tratados no Brasil: bem de consumo, insumo produtivo e, sobretudo, para a geração de energia hidroelétrica, cujo setor exerceu grande influência sobre a gestão (Victorino, 2002).

De fato, o gerenciamento dos recursos hídricos no Brasil tem sido historicamente centralizado e setorial (Victorino, 2003; Abbers \& Jorge, 2005; Novaes \& Jacobi, 2002). A gestão da água se baseava na oferta e o recurso hídrico era tratado sob a ótica do crescimento e desenvolvimento econômicos. O conhecimento sobre os recursos hídricos sempre foi altamente especializado e de domínio em grande parte pelas engenharias.

Os comitês de bacia, previstos na Lei $n^{\circ}$ 9.433/97 (Brasil, 1997), evidenciaram esse campo de disputa ao colocarem em negociação entre técnicos e leigos as decisões sobre a gestão dos recursos hídricos, um dos grandes desafios do sistema. Segundo a Política Nacional de Recursos Hídricos e suas regulamentações, devem participar dos espaços decisórios desde organizações civis de recursos hídricos - técnicas, profissionais ou não - até representantes de povos indígenas e populações tradicionais, o que tornam complexas as formas e métodos de participação, ainda fragilmente implementados dentro do sistema em muitos casos (Veiga, 2007). 
Contudo, o quadro que se desenvolveu a partir da política das águas apresenta, portanto, mudança nos referenciais de representação do território - mais do que a mudança de referência de planejamento do município para a bacia, mas também na relação do homem com uma nova territorialidade (Brito \& Anjos, 2010; Brito, 2008; Marques \& Campos, 2007); novos métodos de gerenciamento e compreensão da água em suas múltiplas dimensões; e o envolvimento dos mais variados atores sociais nos processos de construção técnica e política da tomada de decisão ambiental.

Nesse cenário, o objetivo desse trabalho foi realizar uma análise crítica acerca da crescente relação da EA e os processos de gestão das águas no Brasil, de modo a instigar reflexões sobre que tipo de EA vem sendo desenvolvida paralelamente às transformações mencionadas anteriormente. $\mathrm{O}$ trabalho foi realizado com base em documentos nacionais e internacionais dos dois campos - EA e GIRH; com a observação participante (Gil, 1999) de espaços decisórios no período de 2003 a 2011 que envolviam a Câmara Técnica de Educação, Capacitação, Mobilização Social e Informação em Recursos Hídricos (CTEM/ $\mathrm{CNRH}$ ) e o próprio Conselho Nacional de Recursos Hídricos (CNRH), em que um dos autores ainda faz parte desde sua criação em 2003; e ainda com base em pesquisas envolvendo atores da EA no Sistema Nacional de Gerenciamento dos Recursos Hídricos promovidas pela CTEM em encontros nacionais, cujos dados estão disponíveis no site do próprio CNRH e dados do Sistema de Acompanhamento e Avaliação da Implementação da Política Nacional de Recursos Hídricos (SIAPREH/SRHU/MMA), que estiveram disponíveis no site da Secretaria de Recursos Hídricos (SRHU/MMA).

Nesse sentido, busca-se debater, sem ser conclusivo, sobre qual EA, quer seja no âmbito dos órgãos governamentais ou mesmo no seio do movimento ambientalista, poderia se consolidar e contribuir para a GIRH. E o mais importante, como firmar o papel do(a) educador(a) ambiental em espaços decisórios sobre temas técnicos altamente especializados e dominados por setores com maior poder de negociação, dentro do Sistema Nacional de Gerenciamento dos Recursos Hídricos (SINGREH)?

\section{A EDUCAÇÃO NO CONTEXTO DA GIRH: ANTECEDENTES HISTÓRICOS}

A EA oficial tem suas bases no debate internacional decorrente da $1^{\text {a }}$ Conferência Internacional sobre o Ambiente Humano, realizada em Estocolmo em 1972. Encontros específicos sobre o tema aconteceram posteriormente em Belgrado (em 1975) e Tbilisi (em 1977) lançando de forma global os princípios e diretrizes da EA em declarações que orientaram sua evolução nos países membros da Organização das Nações Unidas (ONU), além de vários encontros e eventos posteriores. Em 1997, o encontro de Thessaloniki chegou à conclusão que os avanços na EA global não atenderam as expectativas geradas ao longo dos anos 1970 (Sorrentino, 2000).

No entanto, em 1991 começa a ficar evidente que no campo dos recursos hídricos reconhecia-se a necessidade de um processo de capacitação de todos os atores envolvidos na gestão das águas. Em um seminário realizado em Delft (em 1991) a "Estratégia para o Desenvolvimento de Capacidades para o Setor Água" é lançada pelo Programa das Nações Unidas para o Meio Ambiente e Desenvolvimento (PNUD). O encontro afirmava o "desenvolvimento de capacidades" como um conceito global e um elemento estratégico para alcançar a sustentabilidade, que deve ser desenvolvido de forma processual e contínua, permeando todas as atividades do setor de recursos hídricos (PNUD, 1991).

O desenvolvimento de capacidades tinha como objetivo aperfeiçoar o processo decisório e a gestão do setor - sob a influência do modelo francês de gestão descentralizada (Veiga, 2007), inserindo o planejamento dos recursos hídricos nas políticas de planejamento nacionais.

$\mathrm{Na}$ Agenda 21, lançada durante Conferência das Nações Unidas sobre o Meio Ambiente e o Desenvolvimento (CNUMAD), popularmente conhecida como Rio 92, o conceito de desenvolvimento de capacidades atrelava-se não só à ampliação de conhecimentos e habilidades técnicas do indivíduo, como nos processos usuais de capacitação, mas envolvia todos os setores que lidavam com a gestão da água, ampliando as habilidades e compreensão crítica individuais sobre sua problemática.

Esse conceito é importante na medida em que os modelos de gestão das águas adotados em muitos países compreendiam atores diversificados em diferentes contextos. Nesse sentido, os processos de capacitação precisavam ir além da simples aquisição individual de conhecimentos, permitindo a construção coletiva de decisões e fortalecendo as instituições de gestão das águas; e ainda resgatando dimensões importantes da gestão, como a questão de gênero e o respeito aos povos tribais e populações tradicionais, entre outros.

No entanto, ficava claro que no cenário internacional existia uma preocupação com a capacitação de pessoas para o aperfeiçoamento das instituições que atuavam na implementação da GIRH. Esse processo só poderia resultar em uma EA de apoio ao aperfeiçoamento dos sistemas de recursos hídricos 
com intervenções desde a educação básica até níveis mais elevados de formação apenas para difundir as políticas e sistemas de gestão, em contraposição à EA crítica debatida no campo dos educadores ambientais em nível nacional.

De fato, a década de 1990 foi marcada pela neoliberalização das políticas públicas e a privatização da prestação de serviços de saneamento básico, entre eles o abastecimento de água. As declarações multilaterais foram, em boa parte dessa década, muito cautelosas no que tange ao direito humano à água. No Brasil, apenas em 1992 constitui-se um Ministério para tratar do meio ambiente, criando uma Secretaria de Recursos Hídricos, onde tudo se alinhava de forma muito precoce - debates e demandas internacionais e o contexto nacional.

Assim, o ano de 1992 nos apresenta dois eventos que marcam tanto o campo da gestão dos recursos hídricos, como a EA. Enquanto a Conferência de Dublin celebrava a GIRH, atribuindo valor econômico à água e tornando o direito básico a ela passível de preços, mesmo que "razoáveis", a Agenda 21 defendia a água como bem social e o "direito básico à água salubre e ao saneamento do meio para a saúde e dignidade de todas as populações humanas".

Cinco anos mais tarde, embora a sua elaboração tivesse iniciado bem anteriormente, a Política Nacional de Recursos Hídricos institui um tripé de gestão composto de agência nacional reguladora, organismos de bacia e órgãos executivos em diferentes níveis, transferindo atribuições para a sociedade em um ambiente altamente tecnocrático, que pouco se ocupava dos pressupostos da água como um direito humano, e mais com sua utilização para fins produtivos.

Contudo, esse embate ainda persiste na atualidade, embora o PNUD (2006) tenha defendido o direito básico à água fundamentando-se no conceito de segurança humana e oportunidade de vida, baseados no Comentário Geral n 15/2002 do Comitê de Direitos Econômicos, Sociais e Culturais da ONU sobre o direito à água. O comentário, entre outras coisas, afirma que para realizar o direito humano à água, essa deve ser considerada suficiente, segura, aceitável, econômica e fisicamente acessível, descrevendo o significado de cada um desses parâmetros.

$\mathrm{O}$ direito humano à água e o tratamento de grupos em situação de vulnerabilidade - seja no meio urbano ou nas áreas semiáridas e em situações de escassez no Brasil - de certa forma sempre alimentaram a leitura crítica que o(a) educador(a) fazem da problemática da água. Mas, quando se trata da relação entre água e educação, as orientações internacionais ficam muito aquém dessa perspectiva crítica necessária para a transformação da sociedade para a sustentabilidade do seu uso.

Inicialmente, uma das razões para tal questão tem base na década de 1990 em que pulverizaram-se pelo país espaços de controle social do emprego de recursos disponibilizados pelas diferentes políticas nacionais - saúde, educação, meio ambiente, etc, na transferência de atribuições do governo federal para as esferas sub-nacionais pós Constituição de 1988 (Veiga, 2007). A setorialização das políticas públicas teve grandes reflexos sobre o gerenciamento dos recursos hídricos, principalmente no que tange à saúde, ao saneamento básico e ao meio ambiente, em que a mesma água, dependendo do processo de apropriação, é tratada por um ou outro órgão governamental.

Atualmente movimentos sociais ainda mantêm representantes em várias frentes de disputa pelo mesmo recurso - água - nos Planos Municipais de Saneamento, Conselhos da Cidade, Conselhos e Comitês de Recursos Hídricos, Conselhos de Saúde, entre outros. Além disso, destaca-se as disparidades entre as regiões brasileiras, as quais vem acentuando as disputas com a entrada de novos atores que, uma vez reconhecidos parte do processo de decisão, enfrentam a alta complexidade para que suas necessidades sejam também reconhecidas.

De fato, o Brasil possui aproximadamente $12 \%$ da disponibilidade de água doce mundial $\left(180.000 \mathrm{~m}^{3} / \mathrm{s}\right.$ como vazão média anual dos rios brasileiros), segundo a Agência Nacional das Águas (ANA, 2007), o que é considerável, se ignorássemos a distribuição desigual no território nacional.

Entretanto, mesmo em diferentes regiões e estados que aparentam uma boa disponibilidade hídrica, desigualdades são encontradas, mas pouco aparecem, como por exemplo, na Bacia do Rio São Francisco, em que embora um rio de grande porte atravesse o sertão nordestino, sua presença não é garantia de acesso à água para milhares de famílias em situação de miséria.

Um estudo feito pelo Ministério das Cidades (MC, 2008) mostrou que pessoas residentes em bairros periféricos ou degradados, com ausência de equipamentos de infraestrutura urbana, tem menor probabilidade de terem acesso à água e ao saneamento do meio, sobretudo quando aumenta o número de moradores por domicílio, se forem pardos, negros e indígenas, se apresentarem baixo grau de instrução e se tiverem portadores de necessidades especiais na família.

Essas desigualdades também estão presentes nas áreas rurais, nos acampamentos de famílias à espera da reforma agrária, entre os povos ciganos, populações em situação de rua, povos quilombolas, entre outros. Povos indígenas, sobretudo, sofrem com 
a contaminação, poluição e escassez das águas de seus territórios por atividades econômicas desenvolvidas nas bacias hidrográficas em que estão inseridas às reservas (INESC, 2004).

Assim, os fundamentos de uma EA para a GIRH não podem se basear apenas na relação do homem ${ }^{1}$ com a água, ou no reconhecimento das mudanças na área da gestão, nem na apropriação do novo território representado pela bacia hidrográfica. Uma EA crítica que alimentou o movimento ambientalista ao longo das últimas décadas, conforme descreve historicamente Paula Júnior (2011) ao elencar os marcos legais e eventos da EA com enfoque na água, deve se apropriar da agenda de luta global pelo reconhecimento do direito à água e consequentemente ao saneamento básico como garantias para o desenvolvimento humano (PNUD, 2006).

Embora o acesso à água esteja no campo do saneamento básico e as águas superficiais e subterrâneas estejam no campo da gestão dos recursos hídricos, nem os educadores nem as escolas devem compreender a água da forma como é fragmentada pelas diferentes políticas públicas ${ }^{2}$, além da dificuldade histórica que possuem para a transversalização de temas inerentes aos conteúdos tradicionais. Por isso, a agenda de luta pela água entre os(as) educadores(as) ambientais deve ser pautada em todas as suas dimensões: gênero, diversidade, equidade, etc.

A cada governo surgem novos materiais ditos pedagógicos de inúmeros órgãos governamentais em diferentes esferas que oferecem uma visão setorial da água numa perspectiva pouco ou nada transversal aos conteúdos tradicionais, que sobrecarregam e exigem dos educadores/professores, geralmente da educação básica, um desempenho extra, fundamentados em interesses muitas vezes distantes da realidade escolar.

Foi nessa perspectiva que a Câmara Técnica de Educação, Capacitação, Mobilização e Informação em Recursos Hídricos (CTEM/CNRH) passou a debater a partir de 2003 a fusão dessas duas agendas: a GIRH

\footnotetext{
$1 \quad$ Com o trabalho inter e multidisciplinar de Diegues (2002) em "Povos e Águas: inventário de áreas úmidas brasileiras", a relação entre grupos sociais e áreas úmidas no Brasil seria muito mais complexa do que se imagina na descrição da relação entre homem e o uso social que este faz dos recursos naturais.

A Educação Ambiental com enfoque nos recursos hídricos é tema de muitos programas, materiais e kits pedagógicos que chegam às escolas por meio de iniciativas do Governo Federal/ Estaduais e ainda de organizações não governamentais nem sempre com a chancela do Ministério da Educação. Entre estes podemos citar o PROCEL da Eletrobrás que aborda a conservação da água e da energia, programa da Agência Nacional de Águas que difunde o sistema de Gestão, o PEAMSS do Ministério das Cidades voltado para o saneamento básico, cartilhas do Ministério da Saúde e FUNASA para a qualidade da água de abastecimento, kits da WWF sobre a conservação da água, entre outros, e as novas agendas sobre riscos e prevenção de cheias, mudanças do clima, etc.
}

e a EA, dentro de suas especificidades e contextos históricos.

Os espaços participativos de deliberação da política de águas expunham seus participantes - dos mais técnicos aos mais leigos - ao jogo de influências dos que detinham o conhecimento e o poder (Veiga, 2007). Nesse sentido, torna-se necessária a capacitação dos atores para enfrentarem os processos decisórios de forma equitativa, e ao mesmo tempo é fundamental construir uma visão sistêmica (holística) sobre a água em nossa sociedade e um maior engajamento social em sua conservação.

Nesse sentido, a Resolução CNRH nº 98/2009 fazia a primeira tentativa de fundir as duas agendas, tentando estimular uma EA contínua e permanente enquanto mantinha os pressupostos do desenvolvimento de capacidades. A perspectiva crítica e reflexiva da EA seria fundamental para a formação de sujeitos comprometidos com a sustentabilidade do uso da água (Veiga \& Branco, 2009) - e ao tratarmos de sujeitos vamos além do mero cidadão, como debate Reigota (2006) e ainda Touraine (1996).

Embora a EA não possa e não dê conta dos conteúdos técnicos e especializados da $\mathrm{GIRH}$, não podemos perder a perspectiva de formação de sujeitos históricos dentro do processo de desenvolvimento de capacidades, ou seja, que a partir de uma reflexão crítica de suas realidades possam intervir e atuar na transformação social necessária para o uso sustentável e proteção da água como função ecológica essencial do meio ambiente global.

Assim, a EA que dialoga com a GIRH deve ir muito além dos aspectos técnicos da gestão e do desenvolvimento de capacidades, ainda que para muitos educadores os aspectos técnicos da gestão sejam limitantes para sua compreensão, releitura e afirmação de si mesmos nos espaços de construção participativa da política de águas. Em geral as organizações não governamentais envolvidas em espaços decisórios de gestão das águas apresentam uma tendência aos assuntos da EA, sensibilização e mobilização social para a GIRH do que os temas mais técnicos do gerenciamento (Veiga, 2007).

A intenção aqui, portanto, é que o(a) educador(a) se reconheçam mais do que simples tradutores de conceitos, como o de bacia hidrográfica, para a sociedade em geral. É necessário que os(as) educadores(as) se afirmem como mediadores e facilitadores da construção da GIRH, mesmo que isso signifique desconstruir a leitura hegemônica do campo de recursos hídricos sobre a água e as relações socioambientais nas bacias hidrográficas. 


\section{A EDUCAÇÃO AMBIENTAL EM DIÁLOGO COM A GIRH}

Uma consideração que deve ser feita ao se tratar da EA e sua contribuição para a GIRH é que não há qualquer intenção de afirmar uma nova EA, cujo tema gerador seja a água. Pelo contrário, reafirma-se o disposto pela Política Nacional de Educação Ambiental (Lei Federal nº 9795/1999 - Brasil, 1999) e por documentos históricos, como o Tratado de Educação Ambiental para Sociedades Sustentáveis e Responsabilidade Global, entre outros.

Tal como o Sistema Nacional de Meio Ambiente teve no IBAMA um importante papel para a formação de educadores com base em uma EA transformadora para os processos de Gestão Ambiental (Quintas, 2000), as especificidades do SINGREH também necessitam que a EA crítica esteja alinhada com os problemas dos espaços decisórios de gestão da água.

Segundo Reigota (2006), a EA construída historicamente no Brasil é crítica e engajada politicamente na transformação social, econômica e ambiental, para não falarmos de outras dimensões. AEA tratada nesse artigo não perde essa perspectiva, mas em paralelo são apresentados alguns contornos do processo político da gestão de recursos hídricos que dão a ela algumas especificidades.

Nos documentos oficiais internacionais de gestão da água a EA foi constantemente convertida em uma formação técnica que permitiria a "conscientização" dos envolvidos. Mas, também em 1992, temos a referência do Tratado de Educação Ambiental para Sociedades Sustentáveis e Responsabilidade Global, documento construído por educadores e representantes da sociedade civil global no âmbito da Conferência das Nações Unidas sobre Meio Ambiente e Desenvolvimento. O Tratado apresenta uma EA que trata a natureza com uma perspectiva abrangente/holística (Sorrentino, 2000), mas também evidencia uma "costura" entre o movimento da EA politizado frente as ditaduras da América Latina e uma EA com menos cunho político dos países do norte (Viezzer, 2004).

No campo da gestão das águas, pode-se dizer que isso fortalece o sentido da EA, que aborda a água em todas as suas dimensões e de forma integrada no meio ambiente, ou seja, não a vê como recurso apenas, mas também como parte importante dos processos ecológicos essenciais, esteja o homem presente ou não no meio.

Essa visão, no campo da educação, permite romper com alguns conceitos relacionados à água e a forma como são ensinados, como por exemplo, o ciclo hidrológico, que é apresentado aos estudantes muitas vezes de forma mecânica e desconsiderando suas relações (Diegues, 2002) com outros eventos ecológicos e socioambientais importantes. Não é a toa que autores como Demetrios Christofidis e Vera Catalão vêm atuando no sentido de estabelecer novos conceitos e metodologias de apoio à EA no campo da gestão da água de forma a complexificar a sua compreensão, tendo a "água como matriz ecopedagógica" (Catalão \& Jacobi, 2011) e a bacia pedagógica ${ }^{3}$.

Além disso, o Tratado visualiza uma EA que fortalece a democracia e a construção de sujeitos comprometidos com sociedades sustentáveis. Isso implica mais do que em uma EA voltada a uma nova interpretação do território e do meio ambiente, mas também voltada para a formação de educadores ambientais críticos que participam e mediam processos de comunicação e tomada de decisão.

A CTEM/CNRH desenvolveu duas breves pesquisas em fóruns nacionais de comitês de bacia (2006 e 2008), cujos resultados estão disponíveis na página eletrônica do CNRH. Dos quase 90 participantes de uma primeira oficina sobre capacitação, menos da metade dos representantes de comitês de bacias presentes ao encontro em Vila Velha-ES, em 2006, participavam de ações de capacitação dos comitês. Contudo, boa parte dessas tratavam-se de ações de EA voltadas para professores e estudantes de escolas locais (www.cnrh.gov.br) ${ }^{4}$. Em 2008, quase 50 participantes de uma mesa redonda informavam que em pelo menos 20 comitês presentes existiam espaços de deliberação sobre a EA (como câmaras técnicas e grupos de trabalho), mas naqueles em que não existiam, a EA era tratada por solicitação dos membros do comitê, da sociedade ou em projetos (www.cnrh. gov.br) $)^{5}$.

Os resultados do Sistema de Acompanhamento da Implementação da Política de Recursos Hídricos - SIAPREH (SRHU, 2010) revelavam que entre os comitês estaduais, $23 \%$ dos eventos realizados entre 2004 e 2006 tratavam-se de ações de EA (embora não se saiba se eram pontuais ou processuais) e boa parte dos eventos, em geral, tinham como público de interesse a sociedade em geral. Entre os 4 comitês federais que responderam à consulta, 3 haviam realizado eventos de EA voltados para usuários e sociedade, de 2004 a 2006; e no mesmo período, os 17 órgãos estaduais respondentes apresentavam como segundo tipo de evento mais realizado aqueles voltados à EA,

$3 \quad$ Na semana da água (23 de marco de 2010) no Distrito Federal, o Prof. Demetrios Christofidis e a Profa. Vera Catalão defenderam a noção de transição da bacia hidrográfica para a bacia pedagógica, no campo educacional.

4 O primeiro autor desse trabalho participou da elaboração, aplicação e sistematização dos resultados dessa pesquisa, estando seus resultados disponíveis na página do Conselho Nacional de Recursos Hídricos como documento das reuniões realizadas pela CTEM.

5 idem. 
juntamente com os voltados para o tema da ouvidoria, perdendo apenas para aqueles que tratavam da gestão dos recursos hídricos (SRHU, 2010).

Os resultados do SIAPREH nos mostram que o SINGREH está "fazendo EA". Se por um lado observamos que não há um acompanhamento e avaliação desses processos, por outro, observamos que o papel do(a) educador(a) no SINGREH fica reduzido a ações de apoio, paralelas à gestão, que nem sempre encontram sustentação permanente. Mas enfim, qual a importância da EA nos espaços de participação e tomada de decisão do SINGREH? Infelizmente não há normatização sobre isso na legislação atual, cuja construção caminha a passos muito lentos, e o processo de monitoramento e avaliação, que parecia ser um caminho em construção, deixou de ser contínuo e permanente, a não ser pelo diálogo entre diferentes entidades nos encontros nacionais das Redes e Fóruns de Organismos de Bacia e EA6. Resta a esperança do fortalecimento dos processos de avaliação dos projetos de EA para a GIRH recomendada por Loureiro (2011) e a necessidade de investigação científica para avaliação dos processos de EA nas bacias hidrográficas, em que as Instituições de Ensino Superior muito têm contribuído.

Isso se faz importante, sobretudo, quando se configuram novas e crescentes fontes de financiamento próprias e contínuas, como é o caso da política de recursos hídricos financiada pela cobrança pelo uso da água. Diferentemente dos orçamentos federais e estaduais para o meio ambiente que são descontínuos, a cobrança pelo uso dos recursos hídricos será permanente e certamente terá recursos destinados à EA, como já acontece com os comitês que têm agências de bacia implantadas.

Entretanto, alguns setores poderiam argumentar que não é possível unificar a $E A$, tendo mais de 150 comitês de bacia desenvolvendo uma mesma EA em todo o Brasil. Não é isso que sugerimos, mesmo porque não seria possível com a multiplicidade de referências com a qual a EA hoje se desenvolve (Carvalho, 2004). Em adição, o Plano Nacional de Recursos Hídricos parece ter sugerido, ao empreender, orientações que vão no sentido de atuar em várias frentes da EA, da educomunicação e do desenvolvimento de capacidades.

Assim, o fundamental é propor que a EA não seja somente técnica (e nos referimos à técnica quando ela se preocupa apenas em traduzir e transmitir conteúdos técnicos), mas também crítica e de preferência que assuma pelo menos contornos do processo

$6 \quad$ O SIAPREH não divulga mais dados sobre pesquisas quantitativas, e a CTEM deixou de produzir regulamentações desde 2009. educativo $^{7}$ (e nesse ponto nos referimos aos aspectos do processo ensino-aprendizagem).

Uma das atribuições do(a) educador(a) ambiental está ligada à análise, qualificação e acompanhamento/avaliação das propostas de EA que são submetidas ou desenvolvidas diretamente pelos comitês de bacia. E quando se trata de qualificar nos referimos ao apoio do(a) educador(a) na melhoria da proposta e do seu desenvolvimento para o alcance não só dos objetivos particulares dessa como também da transformação socioambiental na bacia. Qualquer que seja a metodologia, estratégia ou instrumento de EA utilizados, não devem ser esquecidos ou menosprezados os objetivos de ensino-aprendizagem, e esses estão diretamente relacionados à concepção político-pedagógica da proposta, ao seu projeto de sujeito e ao seu projeto de sociedade. Assim podem ser evitados desperdícios de recursos em ações pontuais voltadas apenas para produção de visibilidade política, e não mudança de comportamento e eficiência na gestão.

O papel dos educadores ambientais não se esgota aqui. Uma outra questão fundamental é a forma como a EA se relaciona com os demais instrumentos de gestão da água previstos na Política Nacional de Recursos Hídricos, bem como com as decisões e formas de planejamento em diferentes áreas de atuação do comitê e territórios da bacia hidrográfica, que Ferraro Júnior (2011) aborda em seus comentários no relato de um encontro de educadores ambientais idealizado pela CTEM e realizado em 2009, Salvador (BA). Embora muitos dos relatos das diferentes atividades desenvolvidas no evento - parte da estratégia de EA do Plano Nacional de Recursos Hídricos - apontem para algumas questões abordadas nesse artigo, o papel dos(as) educadores(as) ambientais ainda continua desvalorizado ou pouco compreendido.

Pode-se dizer que os(as) educadores(as) ambientais são influenciados pelas diferentes agendas de luta que o movimento ambientalista brasileiro foi

$7 \quad$ Quando se trata dos projetos de EA voltados para as bacias hidrográficas, há um histórico de projetos mal formulados que tratavam apenas de aspectos demonstrativos, ações pontuais e que tinham o objetivo como um fim em si mesmo, sem associar um processo de planejamento educacional, dos conteúdos a serem tratados, das reflexões a serem produzidas e sem o referencial de sujeito a ser formado pelo processo educativo, uma falha muito comum em projetos de EA ainda até hoje. Com a mudança das direções de EA nos Ministérios do Meio Ambiente e da Educação a partir de 2003 esses aspectos foram mais enfatizados na busca de substituir as ações pontuais e projetos mal planejados por processos educativos com forte referencial teórico-metodológico, tendo nas obras "Encontros e caminhos: formação de educadoras(es) ambientais e coletivos educadores", Vol. 1 e 2 como seus principais expoentes na reorientação dos novos projetos. Porém, pesquisas do próprio Ministério da Educação mostram que escolas com programas de EA apresentam ações contraditórias em relação ao meio ambiente (Loureiro, 2006). 
assumindo conforme o seu desenvolvimento, sobretudo, nos anos pós-ditadura militar. Isso permitiu a esses atores, que se mantém em constante diálogo com as teorias e debates das redes de EA, reconhecer e dialogar com a diversidade - quer seja de atores sociais ou de representações sociais. Além disso, o(a) educador(a) ambiental tem uma atuação prática junto a grupos sociais que, juntando-se aos fatores anteriores, os revelam com uma grande aptidão para processos de mediação (de conflitos, debates, discussões) e facilitação (de processos de construção, planejamento), extremamente inerentes à gestão participativa da água.

Nos processos de gestão que envolvem a participação social, os(as) educadores(as) ambientais têm o papel de articuladores com uma perspectiva privilegiada de práticas, estratégias e metodologias de construção colaborativa.

Entretanto, de certa forma, vemos que muitos(as) educadores(as) ambientais, quando se trata da temática dos recursos hídricos, possuem um conhecimento limitado ou articulam de maneira frágil os conhecimentos técnicos necessários para se afirmarem e conquistarem respeito nos processos de gestão. Obviamente esse não é um problema apenas dos educadores, mas de boa parte dos atores sociais que participam dos espaços decisórios e de gestão no SINGREH, que não passaram por processos de formação inicial e/ou continuada na área.

A estratégia principal do sistema, nesse sentido, é o desenvolvimento de uma série de cursos de formação, pontual ou de relativa duração, para estender aos participantes do sistema os conhecimentos básicos para elevar seu poder de argumentação e discussão da política. No entanto, estamos perdendo oportunidades de aprendizagem no próprio processo de implementação da política. Isso porque no processo de planejamento raramente são convidados educadores para participarem de sua elaboração e desenvolvimento. $\mathrm{O}$ desenvolvimento de processos de planejamento, quando consideradas estratégias apropriadas de ensino-aprendizagem, apresenta forte caráter educativo por permitirem embates de diferentes visões de mundo, a construção de saberes e debates sobre conhecimentos técnicos em diferentes áreas e campos do saber.

De fato, os resultados do SIAPREH de 2006 (SRHU, 2010) apontam que de 40 comitês estaduais, apenas 10 haviam finalizado seus planos de bacia e 30 estavam em algum ponto mais ou menos avançado de sua construção. Contabilizando-se, pode-se dizer que em mais dos 150 comitês instalados no Brasil, há uma grande oportunidade de se trabalhar o planejamento de forma pedagógica para todos os atores sociais envolvidos e os educadores ambientais são os parceiros ideais para essa mediação. Ainda que não seja definida como processo de aprendizagem, por si só, a construção de planos de bacia já representa uma oportunidade de crescimento em experiência e conhecimento para seus participantes.

Além disso, por meio das Redes de EA, o(a) educador(a) ambiental pode estabelecer sinergias entre as múltiplas ações, projetos, programas e processos educacionais que ocorrem no território da bacia, mesmo que não sejam especificamente com enfoque direto na gestão das águas. A experiência de articulação entre a Itaipu Binacional, o Ministério do Meio Ambiente, o Parque Nacional de Foz do Iguaçu, estado e municípios na Bacia do Paraná III é um bom exemplo disso (Viezzer, 2007).

E por fim, mas não esgotando as múltiplas possibilidades de atuação do(a) educador(a) ambiental no SINGREH, está a sua contribuição na inserção da EA no planejamento da implementação da política de águas. Planos de bacia devem ter seus processos de EA e desenvolvimento de capacidades bem definidos; a outorga e a cobrança devem ser mais do que processos de coerção do uso irracional da água, mas possibilidades de transformação do comportamento de usuários e da sociedade em geral; comitês de bacia devem ter seus próprios programas de EA ou financiar a EA por meio da atuação de entidades variadas em toda a bacia e o enquadramento de corpos d'água pode ter um significado construído e compartilhado pela sociedade na bacia, entre outras possibilidades.

\section{COMITÊS DE BACIA E SISTEMAS DE ENSINO: UMA APROXIMAÇÃO EVIDENTE}

Outro campo de análise que merece destaque diz respeito à inserção dos comitês de bacia nos sistemas de ensino. A relação entre o sistema de gestão de recursos hídricos e os sistemas de ensino é um fato. Bustos (2003) indicou que, de 18 projetos de EA concluídos sob financiamento do FEHIDRO em São Paulo (dos 80 submetidos), 14 tinham como público alvo a escola (ou professores e estudantes).

Entretanto, o que significa trabalhar a EA com enfoque na gestão de águas de forma crítica junto aos sistemas de ensino? Em 2005 a WWF-Brasil apontava em uma pesquisa de amplo alcance que $70 \%$ de entrevistados compreendiam a importância da água, mas apenas $10 \%$ dos respondentes compreendiam a finalidade de um Comitê de Bacia (WWF, 2005).

Em São Paulo, Vargas et al. (2002) já demonstravam que mesmo com mais de uma década de implantação da política estadual de águas, pessoas entrevistadas durante uma pesquisa não sabiam em qual bacia hidrográfica seu município estava inserido, 
muito menos o que seria uma bacia. Esses são alguns dos muitos exemplos que nos levam a reafirmar o que Reigota (2000) defende, adaptando-se suas ideias ao caso da gestão da água. Se os comitês pretendem abordar os sistemas de ensino, uma primeira tarefa do(a) educador(a) ambiental é o de "levantar, analisar e desconstruir as representações sociais" (Reigota, 2000 , p. 113), que tanto eles como os atores sociais do comitê mantêm sobre a água e o meio ambiente.

É claro que quando assumimos a perspectiva do autor não estamos nos referindo a intervenções invasivas entre os atores sociais, mas apontando os seguintes aspectos: quando consideramos a evolução histórica extremamente centralizada do gerenciamento de recursos hídricos no Brasil e sua influência na construção e reconstrução de representações sobre a água nas últimas décadas; quando chamamos os educadores para reavaliarem sua própria visão da água e como podem apoiar uma educação interdisciplinar sob a influência de um pensamento mais complexo e sistêmico; e quando extrapolamos os limites da política de águas para entender as desigualdades causadas por ela ao atender a população de forma genérica sem a devida atenção a grupos socioambientalmente específicos.

Ainda de acordo com Reigota (2000), é necessário, antes de debruçarmos sobre as representações sociais que fundam as ações dos atores em um determinado território, num dado momento histórico, rever e analisar as fragilidades de nossas próprias representações sociais, pois:

Todas as pessoas envolvidas no processo pedagógico têm conhecimentos especificos e representações sociais sobre a problemática ambiental em que elas, as pessoas, estão inseridas cotidianamente. A educação ambiental possibilita e busca a desconstrução de clichês e slogans simplistas sobre as questões ambientais e a construção de um conhecimento mínimo (ou representações sociais qualitativamente melhores) sobre os temas complexos e desafiadores de nossa época (Reigota, 2000, p. 83).

Essa tarefa não é fácil, nem simples, pois as "representações sociais trazem consigo, de forma explícita ou implícita, o potente capital simbólico das instituições, grupos e pessoas que as produzem e divulgam" (Reigota, 2000, p. 93).

Nessa perspectiva, as escolas sempre foram um lócus almejado por gestores públicos para a difusão de informações, em variados formatos e estratégias e com diferentes instrumentos para difusão de políticas públicas, ou seja, se algo não está dando certo, tem que começar pela escola, onde se aprendem novos comportamentos desde cedo. Os comitês de bacia, que se multiplicam, têm um interesse particular nos sistemas de ensino para não só se fazerem conhecidos, mas também preparar os jovens para um mundo onde a questão da água é uma preocupação importante.

Porém, a mudança de comportamento e de valores da população e dos atores da gestão em relação à utilização e conservação da água dificilmente se dá pela promulgação de leis, que não possuem capacidade suficiente para promover o cidadão de consumidor a sujeito político, engajado e responsável (Dowbor, 2005). Acredita-se assim que a educação é o lócus dessa transformação e por isso tantas ONG's se dedicam à $E A$ e, no que tange à gestão das águas, se sentem mais confortáveis com os processos educativos em que têm bastante experiência do que na participação em debates técnicos e especializados (Veiga, 2007).

Em princípio seria uma iniciativa muito oportuna, mas se estamos tratando de uma EA crítica, o seu sentido está justamente em promover uma leitura histórica e contextualizada dos problemas que envolvem o conceito, a política e outros elementos a partir da realidade local, além das representações sociais (sobre a água) dos grupos participantes - no caso professores e estudantes. Para eles, é necessário mais que compreender a gestão da água, mas fazer parte do processo, e se preciso, questioná-lo contribuindo para novos rumos. O planejamento em recursos hídricos toma essa premissa atualmente, quando coloca o Plano Nacional de Recursos Hídricos para avaliação e reorientação de quatro em quatro anos.

Os resultados desse processo podem e devem ser muito variáveis, além de gerarem significados partilhados e legitimados pelos participantes. Apesar das escolas não se tornarem militantes dos comitês de bacia ou da gestão da água, elas podem tornar-se mais críticas em função do próprio processo de aprendizagem na escola ao perceberem que ações como plantio de árvores, limpeza de rios ou reciclagem do lixo podem ser meras ações sem sentido se não houver um projeto de sujeito, e um processo de construção de conhecimento atrelado a uma ação mesmo que pontual. Esses são objetivos da escola, que por mais que não atinjam as expectativas dos comitês de bacia, fazem parte do projeto de sociedade que os mesmos idealizam: o uso sustentável da água para as presentes e futuras gerações.

Não se pode usar um enfoque setorial na escola que limite o desenvolvimento da inter e transdisciplinaridade $^{8}$ na medida em que os conteúdos de meio 8 Os dois conceitos são abordados no campo da educação. O sentido de interdisciplinaridade se dá com base em Fazenda (2002), que embora não possa ser sintetizado de forma tão simplista 
ambiente são fragmentados em temas setoriais. Para a comunidade escolar seriam comitês de meio ambiente/natureza, ou comitês de água somente? Mas, quando essa proposta de reconstrução de conceitos é aceita sem qualquer problema entre os mediadores (professores) e participantes (estudantes ou comunidade escolar), ela geralmente está envolta em um completo desconhecimento local sobre o assunto que permite que os conteúdos e fazeres técnicos atropelem o processo de reflexão crítica e construção partilhada de significados.

Assim, os comitês de bacia podem e devem desenvolver uma relação com os sistemas de ensino por meio da aproximação da vivência, problemas e temáticas debatidas nos espaços de construção da política de águas, que não podem se distanciar da leitura que a comunidade escolar tem dos problemas relacionados à água na esfera local. Essa responsabilidade está não só nos projetos que os comitês ou qualquer outro organismo de bacia desenvolvam diretamente com os sistemas de ensino bem como nos projetos que o comitê apóia financeiramente, após análise e recomendações.

Os comitês devem ser estimulados a constituírem espaços onde a EA seja debatida e contextualizada aos problemas do território das bacias hidrográficas, permitindo que os participantes dos processos de gestão das águas, nos diferentes segmentos, possam construir pontes entre os comitês, a sociedade e os sistemas de ensino, e muitos já o fazem.

Essas pontes prescindem de uma problematização conjunta das questões relativas à água, às bacias hidrográficas e à GIRH, pois somente assim:

"a escola, os conteúdos e o papel do professor e dos alunos são colocados em uma nova situação, não apenas relacionada com o conhecimento, mas sim com o uso que fazemos dele e a sua importância para a nossa participação política cotidiana" (Reigota, 2000, p. 82).

Ao invés do comitê de bacia levar o problema para a escola, essa integração permite que gestores, técnicos, educadores ambientais e sociedade civil organizada problematizem junto com a comunidade escolar, e construam possibilidades de intervenção, em uma alimentação recíproca, pois geralmente ela é unidirecional. Escolas, professores e alunos muitas vezes empreendem esforços pela conservação da

aqui, pressupõe na interação entre disciplinas uma "integração de conhecimentos, visando novos conhecimentos, novas buscas e a transformação da própria realidade". Mais difícil ainda é sintetizar o conceito de transdisciplinaridade, mas nos apoiamos em Morin (2000) para entender a complexidade do mundo por meio do rompimento de fronteiras entre as disciplinas. água que não chegam ao conhecimento ou interesse do comitê, isso devido ao papel mal estruturado dos educadores ambientais dentro do SINGREH. Como aponta Loureiro (2006), o tema mais celebrado nos projetos de EA em escolas é a água, e isso ainda não é pelo apelo das políticas de águas no Brasil.

A escola não deve mais ser usada para o cumprimento dos objetivos das políticas setoriais, e sim reconhecida como participante dos processos de construção do presente e futuro da política, em formatos e estratégias adequados e oportunos. Somente assim os sistemas de ensino podem encontrar significado no seu envolvimento na política de águas, e certamente isso requer um maior desempenho dos(as) educadores(as) ambientais que se responsabilizam pela EA com enfoque na gestão da água, mas também compreensão e comprometimento dos gestores responsáveis pelas políticas de águas.

\section{CONSIDERAÇÕES FINAIS}

A GIRH é fortemente organizada a nível global, com uma agenda política histórica que vem se aperfeiçoando no embate entre grandes interesses econômicos, privatização e os povos sem acesso à água. A EA que luta para mudança global frente às questões ambientais, entre elas o uso sustentável da água, também se apresenta como um processo de forte referência histórica e conteúdo transformador da sociedade e da relação dessa com o meio ambiente.

No seio das instituições governamentais essa transformação é conduzida de forma moderada e descontínua, mas entre os(as) educadores(as) ambientais há forte identidade com as pedagogias de emancipação do sujeito. No entanto, as condições dos espaços de decisão na gestão das águas possuem muitos limitantes para a afirmação do papel dos educadores, como mediadores da transformação social frente à temática da água, sem uma visão fragmentada das políticas setoriais.

Essa transformação só ocorre a partir da compreensão e também da desconstrução das representações sociais que ignoram as agendas de luta pela água, históricas e atuais, que permeiam a atuação dos(as) educadores(as) ambientais na construção de uma EA comprometida com a transformação socioambiental nas bacias hidrográficas, independente da água ser um tema gerador ou não.

No entanto, a utilização apropriada da água como eixo pedagógico nos permite compreender melhor a natureza e promover a reflexão crítica sobre os modelos de desenvolvimento que não conduzem ao uso sustentável da água e nem à gestão integrada 
dos recursos hídricos vem se tornando uma estratégia parceira da gestão.

Por fim, o papel dos educadores ambientais, também enquanto aprendizes das minúcias das políticas de águas em seus embates tecnocráticos deve ser cada vez mais reafirmado para a mediação de processos de participação e planejamento que os põe entre a formação de sujeitos históricos e o cumprimento dos princípios e diretrizes da GIRH, para a sustentabilidade das bacias hidrográficas.

\section{REFERÊNCIAS}

Abbers, R.; Jorge, K. D. 2005. Descentralização da Gestão da Água: Por que os comitês de bacia estão sendo criados? Ambiente e Sociedade, VIII(2): 1-27.

Agência Nacional de Águas (ANA). 2007. GEO Brasil Recursos Hídricos. Brasília, ANA/PNUMA, 264 p.

Brasil. 1997. Lei no 9.433, de 8 de janeiro de 1997. Institui a Política Nacional de Recursos Hídricos, cria o Sistema Nacional de Gerenciamento de Recursos Hídricos, regulamenta o inciso XIX do art. 21 da Constituição Federal, e altera o art. $1^{\circ}$ da Lei $n^{\circ} 8.001$, de 13 de março de 1990, que modificou a Lei $n^{\circ} 7.990$, de 28 de dezembro de 1989. Disponível em: http://www.planalto.gov.br/ ccivil_03/LEIS/I9433.htm. Acesso em: 4 de agosto de 2012.

Brasil. 1999. Lei n 9.795, de 27 de abril de 1999. Dispõe sobre a educação ambiental, institui a Política Nacional de Educação Ambiental e dá outras providências. Disponível em: http://www.mma.gov. $\mathrm{br} /$ port/conama/legiabre.cfm?codlegi=321. Acesso em 4 de agosto de 2012.

Brito, P. L. \& Anjos, R. S. A. 2010. Planejamento territorial: o município $\mathrm{x}$ a bacia hidrográfica. Revista Eletrônica: Tempo - Técnica - Território, 1(1): 22-33.

Brito, T. M. A. 2008. A metamorfose do conceito de região: leituras de Milton Santos. Revista GEOgraphia, 10(20): 74-105.

Bustos, M. R. L. 2003. A educação ambiental sob a ótica dos recursos hídricos. Tese de Doutorado. Universidade de São Paulo. 208p.

Carvalho, I. M. 2004. Educação Ambiental crítica: nomes e endereçamentos da educação. In: Identidades da educação ambiental brasileira. Ministério do Meio Ambiente, Diretoria de Educação Ambientas. Philipe Phomier Layrargues (Coord.). Brasília: Ministério do Meio Ambiente, 156 p.

Catalão, V. L. \& Jacobi, P. 2011. Água como matriz ecopedagógica: uma experiência de aprendizagem significativa e sustentável. In: Política de Águas e
Educação Ambiental: processos dialógicos e formativos em planejamento e gestão de recursos hídricos. MMA/SRHU. Franklin de Paula Júnior e Suraya Modaelli (orgs). Brasília: MMA. 120 p.

Diegues, A, C. S. 2002. Povos e águas: inventário de águas úmidas brasileiras. São Paulo, NUPAUBUSP. 597p.

Fazenda, I. C. A. 2002. Integração e interdisciplinaridade no ensino brasileiro: efetividade ou ideologia. 4. ed. São Paulo, Edições Loyola. 107p.

Ferraro Junior, L. A. 2011. Desafios dos caminhos ambientalistas: um mapa imaginário para transformações democráticas. In: Política de Águas e Educação Ambiental: processos dialógicos e formativos em planejamento e gestão de recursos hídricos. MMA/SRHU. Franklin de Paula Júnior e Suraya Modaelli (orgs). Brasília: MMA. 120 p.

Gil, A. C. 1999. Métodos e técnicas de pesquisa social. São Paulo, Atlas. 207p.

Instituto de Estudos Socioeconômico (INESC). 2004. Orçamento e Política Socioambiental. Ano III, $n^{\circ}$ 9. INES.

Loureiro, C. F. 2011. Avaliação de processos de Educação Ambiental na Gestão das Águas. In: Política de Águas e Educação Ambiental: processos dialógicos e formativos em planejamento e gestão de recursos hídricos.

Loureiro, C. F. 2006. Conteúdos, gestão e percepção da educação ambiental nas Escolas. In: Educação na diversidade: o que fazem as escolas que dizem que fazem educação ambiental / Organização: Rachel Trajber, Patrícia Ramos Mendonça. Brasília: Secretaria de Educação Continuada, Alfabetização e Diversidade. 256 p.

Ministério das Cidades (MC). 2008. Estudo sobre as deficiências de acesso e a probabilidade de cumprimento das metas de desenvolvimento do milênio nos serviços de saneamento básico no Brasil. Brasília, Ministério das Cidades. 237 p.

Marques, A. F. \& Campos, H. A. 2007. Territórios e desenvolvimento. O papel das bacias hidrográficas e do Zoneamento ecológico-econômico. Revista Race, 6(2): 103-116.

Morin, E. 2000. Os Sete Saberes necessários à Educação do Futuro. São Paulo/Brasília, Cortez/ UNESCO.

Novaes, R. C. \& Jacobi, P. R. 2002. Comitês de Bacia, Capital Social, e Eficiência Institucional: Reflexões preliminares sobre influências recíprocas. In: $1^{\circ}$ Encontro da ANNPAS. Anais virtuais.

Paula Junior, F. 2011. Formação, diálogo e participação no planejamento e Gestão de Águas. In: Política de Águas e Educação Ambiental: processos dialógicos e formativos em planejamento e gestão de recursos hídricos. MMA/SRHU. Franklin de 
Paula Júnior e Suraya Modaelli (orgs). Brasília: MMA. 120 p.

Programa De Las Naciones Unidas Para El Desarrollo (PNUD). Desarrollo humano: informe 1991. Bogotá: Tercer Mundo.

Programa das Nacções Unidas para o Desenvolvimento (PNUD). 2006. Beyond scarcity: Power, poverty and the global water crisis. New York, Human Development Report 2006.

Quintas, J. S. 2000. Pensando e praticando a educação ambiental na gestão do meio ambiente. Volume 3 da Coleção Meio ambiente: Série Estudos. Brasília, Edições IBAMA. 161 p.

Reigota, M. 2000. Educação Ambiental: Fragmentos de uma história no Brasil. In: Noal, F. O; Reigota, M.; Barcelos, V. H. de L. (org). Tendências da Educação Ambiental Brasileira. Santa Cruz do Sul: 2. ed: Ed da UNISC, 2000.

Reigota, M. 2006. A educação ambiental frente ao esfacelamento da cidadania no governo Lula (2002-2006). In: XI Simpósio Brasileiro de Pesquisa e Intercâmbio Científico da Associação Nacional de Pós-graduação em Psicologia (ANPEPP). Florianópolis, $32 \mathrm{p}$.

Sorrentino, M. EA pode combater a miséria In: Educação Ambiental seis anos de experiência. São Paulo: WWF - Brasil, 2000. p. 51-53.

Secretaria de Recursos Hídricos e Ambiente Urbano (SRHU). 2010. Resultados do SIAPREH 2006. Disponível em: http://www.mma.gov.br. Acesso em: 10 março 2010.

Touraine, A. 1996. O que é democracia. Petrópolis, RJ: Vozes. $286 \mathrm{p}$.

Vargas, M. C.; Mancuso, M. I. R.; Benze, B. G.; Miranda, C.O. 2002. Água e cidadania: percepção social dos problemas de quantidade, qualidade e custo dos recursos hídricos em duas bacias hidrográficas do interior paulista. In: I Encontro da Associação Nacional de Pós-Graduação e
Pesquisa em Ambiente e Sociedade. São Paulo, 2002.

Veiga, B. G. A. \& Branco, M. 2009. As diretrizes de Educação Ambiental no Sistema Nacional de Gerenciamento dos Recursos Hídricos (SINGREH): a trajetória da Resolução $\mathrm{CNRH} \mathrm{n}^{\circ}$ 98/2009. Revista Coleciona/MMA. 1: 7-13.

Veiga, B. G. A. 2007. Participação social e políticas públicas de águas: olhares sobre as experiências do Brasil, Portugal e França. Tese de Doutorado. Universidade de Brasília, $320 \mathrm{p}$.

Victorino, V. I. P. 2002. Gestão de águas e democracia participativa: uma longa trajetória sócio-política. In: I Encontro da Associação Nacional de pósgraduação e Pesquisa em Meio Ambiente e Sociedade - GT: Teoria e Meio Ambiente, Indaiatuba. Campinas.

Vitorino, V. I. P. 2003. Monopólio, conflito e participação na gestão dos recursos hídricos. Ambiente e Sociedade, $\mathrm{VI}(2)$ : 47-62.

Viezzer, M. L. 2004. Somos todos aprendizes Lembranças da construção do Tratado de Educação Ambiental. Toledo (PR). Disponível em http://forumearebea.org/somos-todos-aprendizeslembrancas-da-construcao-do-tratado-deeducacao-ambiental/. Acesso em março de 2012.

Viezzer, M. L. 2007. Círculos de aprendizagem para a sustentabilidade : caminhada do coletivo educador da Bacia do Paraná III e Entorno do Parque Nacional do Iguaçu. Foz do Iguaçu: ITAIPU Binacional; Ministério do Meio Ambiente. 200 p

World Wide Fund for Nature (WWF). 2005. O que o brasileiro pensa sobre a água. Disponível em: http://www.wwf.org.br. Acesso em 13 dezembro 2005. 